\title{
The effect of parathyroidectomy on quality of life in primary hyperparathyroidism: evaluation with using sf-36 and phpqol questionnaire
}

\author{
Erkan Somuncu and Yasin Kara
}

Department of General Surgery, University of Health Sciences, Kanuni Sultan Suleyman Training and Research Hospital, Istanbul, Turkey

\begin{abstract}
Quality of life (QoL) typically improves with a parathyroidectomy (PTx) in cases of primary hyperparathyroidism (PHPT), but the effect of surgery on QoL is not yet fully understood. This study evaluated the impact of PTx on health-related QoL (HRQoL). Patients who underwent PTx for PHPT between January 2016 and December 2019 were asked to complete the 36-Item Short Form Health Survey (SF-36) and the Primary Hyperparathyroidism Quality of Life (PHPQoL) questionnaire before surgery and 1 year later. A 5-point Likert scale was used: negative responses received a lower score and positive responses scored high. Forty-one of 50 patients completed the questionnaires before and 12 months after the surgery. The median patient age was 64 years (min-max: 32-83 years). In the study group, 33 were female, and 8 were male. The SF-36 results indicated that significant improvements had been observed in all 8 domains a year after surgery, particularly in the physical functioning and role, general health, energy, and mental health scales. The PHPQoL scores also improved significantly after PTx $(p<0.05)$. The improvement in the physical and mental health components was $50 \%$ and $76 \%$, respectively. In conclusion, this study demonstrated that PTx for PHPT improved QoL.
\end{abstract}

Key words: Parathyroidectomy, Primary hyperparathyroidism quality of life (PHPQoL), Primary hyperparathyroidism, Quality of life, 36-Item short form health survey (SF-36)

PRIMARY HYPERPARATHYROIDISM (PHPT) is a condition in which 1 or more parathyroid glands gain autonomy and secrete an excessive quantity of parathyroid hormone. PHPT occurs in $0.2 \%$ to $0.5 \%$ of the population. It is the most common cause of hypercalcemia in outpatients and the second after cancer in inpatients [1]. A parathyroidectomy (PTx) is the preferred standard treatment for patients with obvious symptoms and complications of PHPT. Asymptomatic patients with fatigue, irritability, and mood swings often comprise the majority of cases [2]. Various guidelines have been developed for the surgical treatment of PHPT. However, the effects of PTx on improving symptoms and quality of life (QoL) have not been evaluated in guidelines because the best assessment of the result of treatment is the patient's perception $[3,4]$.

The aim of this study was to review the HRQoL of

Submitted Jul. 1, 2020; Accepted Jul. 30, 2020 as EJ20-0417 Released online in J-STAGE as advance publication Sep. 2, 2020 Correspondence to: Erkan Somuncu, MD (Consultant), Atakent Neighbourhood, Turgut Özal Avenue No: 46/1, Küçükcekmece, Istanbul, Turkey.

E-mail: dr.somuncu@gmail.com patients who underwent PTx for PHPT using 2 questionnaires.

\section{Materials and Methods}

\section{Participants}

The ethics committee of Kanuni Sultan Suleyman Training and Research Hospital approved this study. In the 3-year period of January 2016-December 2019, a total of 50 patients underwent PTx due to PHPT. All of the operations were performed by a single endocrine surgeon. Patients who had histopathologically proven adenoma were included, while cases of parathyroid cancer, hyperplasia, or incidental PTx during thyroid surgery were eliminated. Patient demographic, laboratory, operative, and histopathological data were recorded and analyzed.

The QoL assessment tools used were the 36-Item Short Form Health Survey (SF-36) and the Primary Hyperparathyroidism Quality of Life (PHPQoL) questionnaire. The patients were asked to complete the PHPQoL and the SF-36 before and 12 months after surgery. The postoperative responses were provided at a 
Table 1 PHPQoL Questionnaire [14]

\begin{tabular}{|c|c|c|c|c|c|}
\hline Questions & $\begin{array}{l}\text { Always } \\
\text { (score 0) }\end{array}$ & $\begin{array}{c}\text { Many } \\
\text { times } \\
\text { (score 1) }\end{array}$ & $\begin{array}{c}\text { From time } \\
\text { to time } \\
\text { (score 2) }\end{array}$ & $\begin{array}{c}\text { Hardly } \\
\text { ever } \\
\text { (score 3) }\end{array}$ & $\begin{array}{c}\text { Never } \\
\text { (score 4) }\end{array}$ \\
\hline
\end{tabular}

A) Physical functioning domain

1. I have felt sleepy after getting up in the morning and it has been hard to get going

2. I have felt weak

3. I have found it hard to walk for a long time

4. I have noticed I get short of breath when I walk quickly

5. I have had back pain

6. My bones and/or joints have ached

7. I have found it difficult to carry out my daily activities

8. I have restricted some of my leisure activities

9. I have restricted what household chores I do

B) Emotional functioning domain

10. I have been irritable

11. I have felt depressed

12. The illness has stopped me from sleeping well

13. I have woken up during the night

14. I have found it hard to concentrate

15. I have been worried, not only about the illness but also its complications

16. I have noticed I find it more difficult to concentrate at work than before

Abbreviation: PHPQoL, Primary Hyperparathyroidism Quality of life.

follow-up visit or via e-mail. Clinical data were recorded retrospectively for correlation with changes in the $\mathrm{QoL}$ reported by the participants.

\section{Tools for quality of life assessment}

The SF-36 survey is a popular and validated measure of generic HRQoL that is used worldwide in clinical trials. The answers to 36 questions are used to calculate scores in 8 domains of health: general health perception, physical function, physical and emotional role limitations, social function, bodily pain, mental health, and vitality. These scores are then used to calculate 2 summary scores: the Physical Component Summary (PCS) and the Mental Component Summary (MCS). These scores were standardised to a Turkish population norm score, where the mean was set to 50 and the standard deviation was 10 [5]. The preoperative and postoperative domain scores as well as the PCS and MCS scores were compared.

The second assessment used was the PHPQoL questionnaire, which was developed in Spanish and then translated into English using the proposed standard methodology [6]. We translated the questionnaire into Turkish for our participants. As shown in Table 1, the PHPQoL has 16 items and only 1 dimension. Each item is scored on a Likert-type scale ranging from 0 to 4 (always, many times, from time to time, hardly ever, and never). The total score ranges from 0 to 64 and is standardized from 0 (worst QoL) to 100 (best QoL) by applying the formula:

[(obtained score) - (minimum score $)] /[$ (maximum score) $-($ minimum score $)] \times 100$.

\section{Statistical analysis}

The data analysis was performed using IBM SPSS Statistics for Windows, Version 22.0 (IBM Corp., Armonk, NY, USA). The scores are presented as mean \pm $\mathrm{SD}$. The non-parametric paired Wilcoxon signed-rank test was used to compare the peroperative and postoperative data since the scores were found to be normally distributed. A $p$ value of $<0.05$ was considered statistically significant. The relationship between variables was assessed using Spearman's Rank Correlation Coefficient. 


\section{Results}

\section{Baseline and postoperative data of the participants}

A total of 50 patients were recruited from the period of 2016-2019. They were all operated on by a single surgeon. Forty-one $(82 \%)$ of the participants completed all of the questionnaires. The mean age of the patients was $60.4 \pm 12.36$ years. There were 33 female and 8 male patients in the study. All of the patients had parathyroid adenoma. The formal education level of most of the participants was low. The mean duration from diagnosis to PTx was $11 \pm 4$ months, without a significant difference between the sexes. A total of $75.6 \%$ of patients presented with chronic concomitant diseases (hypertension: $61.4 \%$, hypercholesterolemia: $39.6 \%$, diabetes mellitus: $23.6 \%$, etc.), without a significant difference between the sexes (Table 2).

The preoperative baseline mean slow component A (SCa) level was $11.44 \pm 1.07 \mathrm{mg} / \mathrm{dL}$ and the mean intact parathyroid hormone (iPTH) level was $211.63 \pm 187$

Table 2 Sociodemographic clinical features of PHPT patients

\begin{tabular}{lcc}
\hline & $n$ & Mean SD $\%$ \\
\hline Mean age (SD) (y) & 41 & $60.4(12.3)$ \\
Sex & 8 & $19.6 \%$ \\
$\quad$ Men & 33 & $80.4 \%$ \\
$\quad$ Women & & \\
Educational level & 26 & $63.4 \%$ \\
$\quad$ Low & 9 & $21.9 \%$ \\
$\quad$ Moderate & 6 & $14.7 \%$ \\
$\quad$ Advanced & 31 & $75.6 \%$ \\
Chronic concomitant diseases & & $11(4)$ \\
\hline Time to diagnose (months) & & \\
\hline
\end{tabular}

Abbreviations: PHPT, primary hyperparathyroidism. $\mathrm{pg} / \mathrm{mL}$, as could be expected. The most common symptoms of PHPT at baseline were muscle weakness and pain $(90.2 \%)$, fatigue $(68.2 \%)$, constipation $(56 \%)$ and depression (43.9\%). At the postoperative 12th month, the mean sCa level was $9.47 \pm 0.71 \mathrm{mg} / \mathrm{dL}$ and the mean iPTH level was $59.77 \pm 35.57 \mathrm{pg} / \mathrm{mL}$. The laboratory results had recovered to normal levels (Table 3 ).

\section{Results of SF-36 survey}

The scores of all 8 domains of the SF-36 before and after surgery are shown in Fig. 1 with a reference line of 50. High scores indicate a better QoL. Before the operation, the scores of all 8 components were lower than the population norm. However, at 12 months after surgery, all of the scales showed improvement. As shown in Table 4, the improvement in physical functionality and role, general health, energy, and mental health was statistically significant. Statistically insignificant improvements in overall health perception $(p=0.135)$ and body pain $(p=0.071)$ were also observed. The most significant increase in the QoL was seen in the energy score ( $p$ $=0.011)$. Both the PCS and MCS scores improved significantly following surgery. The mean of the total SF-36 score of the 8 health concepts was $64 \pm 20$ before PTX and $98 \pm 18$ after 12 months $(p<0.05)$.

\section{Results of PHPQoL survey}

There was a statistically significant improvement in the PHPQoL scores after PTX. As shown in Fig. 2, the preoperative mean score was $48 \pm 22$ and the 12 th month mean was $62 \pm 24(p<0.05)$. The first 9 questions of the PHPQoL assess physical domains. The mean preoperative and postoperative score for this section was $18 \pm 0.4$ and $27 \pm 0.3$, respectively. The remaining 7 questions are defined as emotional domains. The mean preoperative and postoperative scores for this portion was $13 \pm 0.2$ and $23 \pm 0.8$, respectively. According to these scores, the

Table 3 Clinical changes during follow-up of PTXs

\begin{tabular}{|c|c|c|c|c|}
\hline & \multicolumn{2}{|c|}{ Preoperative baseline } & \multicolumn{2}{|c|}{ Postoperative 12.th month } \\
\hline & $n$ & Mean $S D / \%$ & $n$ & Mean $S D / \%$ \\
\hline sCa levels (mg/dL) & 41 & $11.44(1.07)$ & 41 & $9.47(0.71)$ \\
\hline iPTH levels (pg/mL) & 41 & $211.63(187)$ & 41 & $59.77(35.57)$ \\
\hline \multicolumn{5}{|l|}{ PHPT symptoms (most mentioned) } \\
\hline Muscle weakness and pain & 37 & $90.2 \%$ & 21 & $51.2 \%$ \\
\hline Fatigue & 28 & $68.2 \%$ & 16 & $39 \%$ \\
\hline Constipation & 23 & $56 \%$ & 13 & $31.7 \%$ \\
\hline Depression & 18 & $43.9 \%$ & 11 & $26.8 \%$ \\
\hline
\end{tabular}

Abbreviations: sCa, serum calcium; iPTH, intact Parathyroid hormone; PHPT, primary hyperparathyroidism; PTXs, parathyroidectomies. 
Table 4 Preoperative and postoperative values of all eight areas evaluated in SF-36 form with the physical component and mental component score. $P<0.05$ value is considered statistically significant between pre and postoperative scores. Data are presented as mean \pm SD

\begin{tabular}{lccc}
\hline Domains & Before Surgery & After Surgery & $p$ value \\
\hline Physical functioning (PF) & $35.1(1.2)$ & $51.2(1.4)$ & 0.016 \\
\hline Social functioning (SF) & $45.2(1.1)$ & $48.3(1.2)$ & 0.431 \\
Physical role limitation (PRL) & $43.3(1.4)$ & $52.2(1.6)$ & 0.237 \\
\hline Emotional role limitation (ERL) & $40.4(1.4)$ & $42.8(1.5)$ & 0.414 \\
Energy (EN) & $41.7(1.7)$ & $55.3(1.4)$ & 0.011 \\
\hline Mental health (MH) & $43.9(1.6)$ & $53.2(1.3)$ & 0.026 \\
General health (GH) & $45.7(1.4)$ & $51.4(1.5)$ & 0.135 \\
\hline Body pain (PA) & $41.1(1.3)$ & $49.2(1.6)$ & 0.071 \\
Summary & & & \\
Physical component summary score (PCS) & $26.8(1.6)$ & $33.4(1.9)$ & 0.028 \\
Mental component summary score (MCS) & $39.5(1.4)$ & $54.2(1.5)$ & 0.004 \\
\hline
\end{tabular}

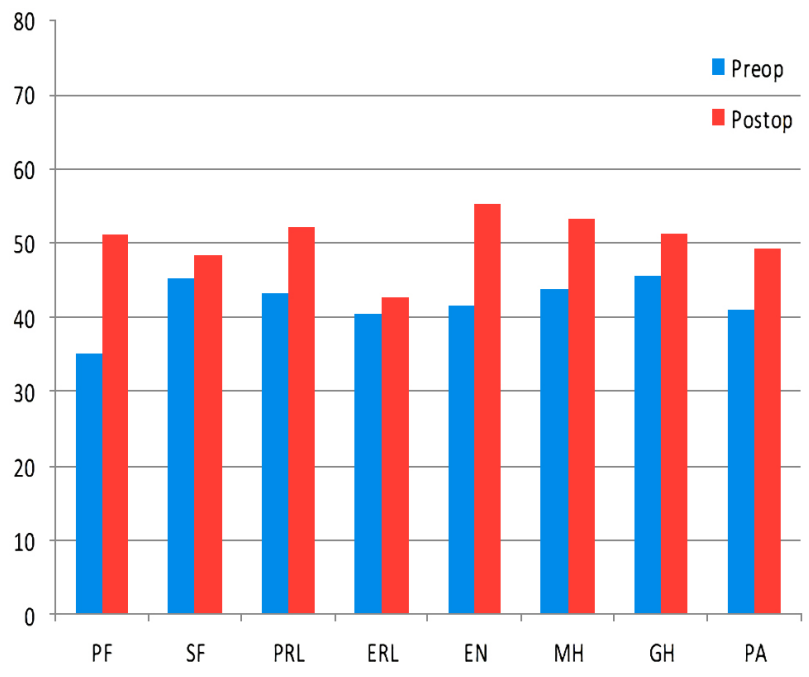

Fig. 1 Scores before parathyroidectomy and 12 months after surgery according to the 8 domains of the 36-Item Short Form Health Survey (SF-36).

EN, Energy; ERL, Emotional role limitation; GH, General health; MH, Mental health; PA, Body pain; PF, Physical functioning; PRL, Physical role limitation; SF, Social functioning

clinical improvement was $50 \%$ in physical component and $76 \%$ in the emotional component.

\section{Discussion}

The definitive treatment for PHPT is surgery. A minimally invasive parathyroidectomy has been increasingly adopted in most advanced centers and has been proven to be a safe and effective method to treat PHPT [7-10]. As technical advances in surgery increase, it may not be

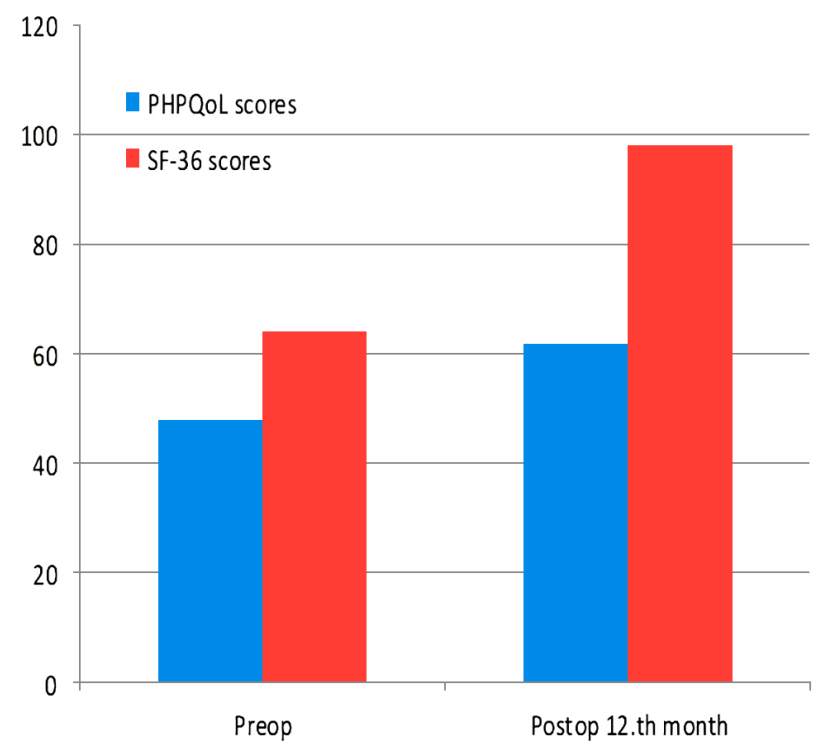

Fig. 2 Total scores of the 36-Item Short Form Health Survey (SF-36) and the Primary Hyperparathyroidism Quality of Life (PHPQoL) before parathyroidectomy and 12 months after surgery.

enough to evaluate procedures with only surgical results. More criteria that measure QoL should be considered. It is well known that surgical treatment generally improves QoL in cases of PHPT. However, evaluating QoL can be challenging with imperfect results [11-14]. In this study, changes in the patient's perceived QoL were recorded before and after PTx. Since PHPT is typically either asymptomatic or has varied symptoms, we selected comprehensive surveys that are widely used to measure overall health.

In an observational study, Webb et al. [15] 
administered the PHPQoL questionnaire to 104 patients who underwent PTx for PHPT. They reported that the mean score of 52 before PTx demonstrated improvement at 3 months, with a mean score of 61 ; however, the score remained constant at the 6 th and 12 th months. The possible benefit of PTX on QoL is sometimes questioned due to the clinical variations of PHPT with milder symptoms. The PHPQoL is a tool that evaluates recent QoL. It measures the impact in 2 areas: physical and emotional/neuropsychological functions. It is a diseasespecific questionnaire that measures symptoms of daily life that are important to patients. This potential benefit can be distinguished from the SF-36, which assesses overall health and well-being [16].

In another study, Ejlsmark-Svenson et al. [17] found a median PHPQoL score of 75 (min-max: 20-92) at the time of diagnosis and 79 (min-max: 39-95) after PTx. They concluded that there was a improvement in QoL. They found that the less significant increase in HRQoL was due to the better score initially recorded. In our study, the mean PHPQoL score was $48 \pm 22$ at the time of diagnosis, and the mean score measured at the 12th month after PTx was $62 \pm 24$. The total PHPQoL score was lower in our population compared with these studies [15-17]. Nonetheless, we found a significantly improved QoL 12 months after the surgery. We classified the patients as symptomatic or asymptomatic according to the level of ionized calcium, age, and organ symptoms that can only be attributed to PHPT. We did not find any significant difference in the scores between symptomatic and asymptomatic patients, as Ejlsmark-Svenson et al. [17] also reported. In contrast, Webb et al. [15] found a lower PHPQoL score in symptomatic patients compared with asymptomatic patients. Presumably, this is because the PHPT onset is milder in asymptomatic patients than in patients with extensive symptoms, as has been described in the literature.

This is the first study to evaluate the PHPQoL questionnaire in the Turkish clinical setting and more research on this topic is needed. We did not find a correlation between biochemical data and QoL. This is consistent with most other studies, which have also reported that there was no correlation between QoL and biochemical indices in PHPT [15-18].

In the literature, the effect of PTx on patients with PHPT has been evaluated using non-disease specific questionnaires such as the SF-36 and many other HRQoL questionnaires [19-28]. Rolighed et al. [29] reported that HRQoL as assessed using the SF-36 was low in all 8 areas compared with a healthy control group. However, when the analysis was limited to include only those with asymptomatic disease, the result was low in only 1 area (viability) compared with the controls. In 3 randomized controlled trials using the SF-36, PTx achieved a modest improvement in 2 to 4 areas (emotional, social function, general health, and vitality) compared with a medically monitored group [30-32]. Another randomized controlled study that used this questionnaire found that the group that underwent PTx showed a slight but not significant difference in the emotional role and physical scales. The score on the mental health subscale was lower during 2 years of follow-up [33].

Currently, most studies that use the SF-36 report an improvement in HRQoL following surgery. In our research, the results in 4 domains (energy, physical functioning and role, general health, and mental health) of the SF-36 improved after PTx. More surveys are needed to determine the most appropriate questionnaire to fully evaluate the effect of PTx in PHPT.

This study was not a randomized controlled trial, which may be considered a limitation. PTx was performed only in patients diagnosed with PHPT. Partial recovery after surgery may be due to the perception that surgery can treat the disease. Although there is literature for norm values in the Turkish population for the SF-36, the lack of community studies for the PHPQoL that are specific to the disease limited us. The SF-36 and the PHPQoL provide information about QoL, but not about cognitive functions or other sequelae. Our study sample was too small to analyze these results, and more extensive studies with a larger sample size are needed to evaluate the long-term effects of PTx in patients with PHPT.

In conclusion, this study evaluated QoL in patients with PHPT using the SF-36 and the PHPQoL before and after surgery. In terms of physical impact, overall health, and energy score, the preoperative QoL of the patients with PHPT was significantly lower than the score recorded after surgery. We found that the PHPQoL questionnaire was a specific HRQoL tool with excellent psychometric properties that can evaluate the results as reported patients in Turkish society. The results of both assessment tools indicated that suitable patients with PHPT can benefit from surgical treatment.

\section{Acknowledgement}

The authors would like to thank Dr. Osman Sibıç and Dr.İsmail Hakkı Alp Solak for their assistance with this article.

\section{Disclosure}

The authors declare that there is no conflict of interest associated with this manuscript. 


\section{References}

1. Eigelberger MS, Cheah WK, Ituarte PH, Streja L, Duh QY, et al. (2004) The NIH criteria for parathyroidectomy in asymptomatic primary hyperparathyroidism: are they too limited? Ann Surg 239: 528-535.

2. Greutelaers B, Kullen K, Kollias J, Bochner M, Roberts A, et al. (2004) Pasieka illness questionnaire: its value in primary hyperparathyroidism. ANZ J Surg 74: 112-115.

3. Bilezikian JP, Brandi ML, Eastell R, Silverberg SJ, Udelsman R, et al. (2014) Guidelines for the management of asymptomatic primary hyperparathyroidism: summary statement from the Fourth International Workshop. J Clin Endocrinol Metab 99: 3561-3569.

4. Leong KJ, Sam RC, Garnham AW (2010) Health-related quality of life improvement following surgical treatment of primary hyperparathyroidism in a United Kingdom population. Surgeon 8: 5-8.

5. Yucel Demiral, Gul Ergor, Belgin Unal, Semin S, Akvardar Y, et al. (2006) Normative data and discriminative properties of short form 36 (SF-36) in Turkish urban population. BMC Public Health 6: 247.

6. Webb SM, Puig-Domingo M, Villabona C, Muñoz-Torres M, Farrerons J, et al. (2013) Development of a new tool for assessing health-related quality of life in patients with primary hyperparathyroidism. Health Qual Life Outcomes 11: 97.

7. Shabtai M, Ben-Haim M, Muntz Y, Vered I, Rosin D, et al. (2003) 140 consecutive cases of minimally invasive, radio-guided parathyroidectomy: lessons learned and long-term results. Surg Endosc 17: 688-691.

8. Chen H (2004) Radioguided parathyroid surgery. Adv Surg 38: 377-392.

9. Satchie B, Chen H (2005) Radioguided techniques for parathyroid surgery. Asian J Surg 28: 77-81.

10. Adler JT, Sippel RS, Chen H (2008) The influence of surgical approach on quality of life after parathyroid surgery. Ann Surg Oncol 15: 1559-1565.

11. Burney RE, Jones KR, Coon JW, Blewitt DK, Herm AM (1996) Assessment of patient outcomes after operation for primary hyperparathyroidism. Surgery 120: 1013-1018.

12. Burney RE, Jones KR, Peterson M, Christy B, Thompson NW (1998) Surgical correction of primary hyperparathyroidism improves quality of life. Surgery 124: 987-991.

13. Pasieka JL, Parsons LL (1998) Prospective surgical outcome study of relief of symptoms following surgery in patients with primary hyperparathyroidism. World J Surg 22: $513-518$.

14. Sheldon DG, Lee FT, Neil NJ, Ryan JA Jr (2002) Surgical treatment of hyperparathyroidism improves health-related quality of life. Arch Surg 137: 1022-1026.

15. Webb SM, Puig-Domingo M, Villabona C, Muñoz-Torres M, Marazuela M, et al. (2016) Validation of PHPQoL, a disease-specific quality-of-life questionnaire for patients with primary hyperparathyroidism. J Clin Endocrinol Metab 101: 1571-1578.
16. Brazier JE, Harper R, Jones NM, O'Cathain A, Thomas KJ, et al. (1992) Validating the SF-36 health survey questionnaire: new outcome measure for primary care. $B M J$ 305: 160-164.

17. Ejlsmark-Svensson H, Sikjaer T, Webb SM, Rejnmark L, Rolighed L (2019) Health-related quality of life improves 1 year after parathyroidectomy in primary hyperparathyroidism: a prospective cohort study. Clin Endocrinol (Oxf) 90: 184-191.

18. Tsukahara K, Sugitani I, Fujimoto Y, Kawabata K (2008) Surgery did not improve the subjective neuropsychological symptoms of patients with incidentally detected mild primary hyperparathyroidism. Eur Arch Otorhinolaryngol 265: 565-569.

19. Burney RE, Jones KR, Christy B, Thompson NW (1999) Health status improvement after surgical correction of primary hyperparathyroidism in patients with high and low preoperative calcium levels. Surgery 125: 608-614.

20. Edwards ME, Rotramel A, Beyer T, Gaffud MJ, Djuricin $\mathrm{G}$, et al. (2006) Improvement in the health-related quality of life symptoms of hyperparathyroidism is durable on long-term follow-up. Surgery 140: 655-663.

21. Caillard C, Sebag F, Mathonnet M, Gibelin H, Brunaud L, et al. (2007) Prospective evaluation of quality of life (SF-36v2) and nonspecific symptoms before and after cure of primary hyperparathyroidism (1-year follow-up). Surgery 141: 153-159.

22. Ramakant P, Verma AK, Chand G, Mishra A, Agarwal G, et al. (2011) Salutary effect of parathyroidectomy on neuropsychiatric symptoms in patients with primary hyperparathyroidism: evaluation using PAS and SF-36v2 scoring systems. J Postgrad Med 57: 96-101.

23. Blanchard C, Mathonnet M, Sebag F, Caillard C, Kubis C, et al. (2014) Quality of life is modestly improved in older patients with mild primary hyperparathyroidism postoperatively: results of a prospective multicenter study. Ann Surg Oncol 21: 3534-3540.

24. Dulfer R, Geilvoet W, Morks A, Van Lieshout EM, Smit $\mathrm{CP}$, et al. (2016) Impact of parathyroidectomy for primary hyperparathyroidism on quality of life: a case-control study using Short Form Health Survey 36. Head Neck 38: 1213-1220.

25. Bannani S, Christou N, Guérin C, Hamy A, Sebag F, et al. (2018) Effect of parathyroidectomy on quality of life and non-specific symptoms in normocalcaemic primary hyperparathyroidism. Br J Surg 105: 223-229.

26. Murray SE, Pathak PR, Pontes DS, Schneider DF, Schaefer SC, et al. (2013) Timing of symptom improvement after parathyroidectomy for primary hyperparathyroidism. Surgery 154: 1463-1469.

27. Ryhänen EM, Heiskanen I, Sintonen H, Välimäki MJ, Roine RP, et al. (2015) Health-related quality of life is impaired in primary hyperparathyroidism and significantly improves after surgery. Endocr Connect 4: 179-186. 
28. Storvall S, Ryhänen EM, Heiskanen I, Sintonen H, Roine RP, et al. (2017) Surgery significantly improves neurocognition, sleep, and blood pressure in primary hyperparathyroidism: a 3-year prospective follow-up study. Horm Metab Res 49: 772-777.

29. Rolighed L, Amstrup AK, Jakobsen NFB, Sikjaer T, Mosekilde L, et al. (2014) Muscle function is impaired in patients with "asymptomatic" primary hyperparathyroidism. World J Surg 38: 549-557.

30. Talpos GB, Bone HG 3rd, Kleerekoper M, Phillips ER, Alam M, et al. (2000) Randomized trial of parathyroidectomy in mild asymptomatic primary hyperparathyroidism: patient description and effects on the SF-36 health survey. Surgery 128: 1013-1020.

31. Rao DS, Phillips ER, Divine GW, Talpos GB (2004)
Randomized controlled clinical trial of surgery versus no surgery in patients with mild asymptomatic primary hyperparathyroidism. J Clin Endocrinol Metab 89: 54155422 .

32. Ambrogini E, Cetani F, Cianferotti L, Vignali E, Banti C, et al. (2007) Surgery or surveillance for mild asymptomatic primary hyperparathyroidism: a prospective, randomized clinical trial. J Clin Endocrinol Metab 92: 3114-3121.

33. Bollerslev J, Jansson S, Mollerup CL, Nordenström J, Lundgren E, et al. (2007) Medical observation, compared with parathyroidectomy, for asymptomatic primary hyperparathyroidism: a prospective, randomized trial. J Clin Endocrinol Metab 92: 1687-1692. 